\title{
Baux's and Abbreviated Burn Severity Score for the Prediction of Mortality in Patients with Acute Burn Injury
}

\author{
Peeyush Dahal $^{1}$, Sanjita Ghimire ${ }^{2}$, Nirvan Kumar Maharjan ${ }^{1}$, Shankar Man Rai ${ }^{1}$ \\ ${ }^{1}$ National Academy of Medical Sciences, Faculty of Burns and Plastic surgery, Kathmandu \\ ${ }^{2}$ Nepal Police Hospital
}

\section{Correspondence \\ Dr. Peeyush Dahal \\ National Academy of Medical \\ Science, Bir Hospital, \\ Kathmandu \\ Email: \\ peeyushdahal@gmail.com}

DOI: http://dx.doi.org/10.3126/ jcmsn.v11i4.14321

\begin{abstract}
Background \& Objectives: Prediction of outcome for patients with major thermal injury is important to inform clinical decision making, alleviate individual suffering and improve hospital resource allocation. Early prediction of outcome (i.e., survival or mortality) may help triage effectively, and to implement medical and surgical interventions efficiently as soon as possible. Burn mortality has decreased markedly with the improvement in burn management in the past 100 years, and multiple burn mortality prediction models have been developed over these times in response to that decline. But these services are still not enough to reduce the burn related injuries in low income country like Nepal. So we did a study to observe the effectiveness of two different but very popular models (Baux and ABSI) in our context. Materials \& Methods: This was a prospective observational study where 92 cases of severe burn injury was selected and the results were compared with Baux and ABSI scoring system. Results: Total admission was 140 and mortality was 33. Out of these admission 92 cases of severe burn injury was selected for the study. Most $(85.8 \%)$ of were among the young group 16-40 years. It comprises $41.3 \%$ in total. In total $63.7 \%$ were female. Mortality with severe burn injury was $29.3 \%$. No death had occurred below the Baux's score 30 and there was more than $51 \%$ mortality above the score of 60 . There was no mortality with ABSI scoring $<3$ and mortality was high in ABSI scoring $>$ 6.Conclusion: Baux and ABSI score systems are simple to calculate and ABSI is more accurate for prediction of acute burn injury.

Key words: ABSI Score, Baux score, Burn mortality, Threat to life, TBSA.
\end{abstract}

Citation: Dahal P, Ghimire S, Maharjan N, Rai SM. Prediction of Outcome of Acute Burn Injury by Baux's and Abbreviated Burn Severity Index Score. JCMS Nepal. 2015;11(4):24-27.

\section{INTRODUCTION}

Burn injuries and their sequelae are important public health problem in developing country. Annually fire-related burns are responsible for about 265,000 deaths in the world. Over $90 \%$ of fatal fire-related burns occur in developing or lowand middle-income countries (LMICs) with SouthEast Asia alone accounting for over half of these fire-related deaths. More girls in South East Asia Region die of fires than of tuberculosis, HIV/AIDS and malaria combined. $95 \%$ of burn deaths occur in LMIC. Mortality rate among Low income country is 11 times higher than in high income country. Severity of burns increases with decreasing socioeconomic status.

The reported mortality rate due to burns in different Asian countries is variable lowest in Kuwait and highest in India. We assume that the incidence and mortality rate is higher in Nepal.

Prediction of outcome for patients with major thermal injury is important to inform clinical decision making, alleviate individual suffering and improve hospital resource allocation. Early prediction of outcome (i.e., survival or mortality) may help triage effectively, and to implement medical and surgical interventions efficiently as soon as possible. These estimates would also be useful to patients' families and medical professionals making medical and financial decisions regarding their care. As a result the better care could reduce hospital complications, shorten length of stay, improve quality of life, and enhance survival.

Burn mortality has decreased markedly in the past 100 years, and multiple burn mortality prediction models have been developed over time in response 
to that decline. Mortality prediction models are important for quality control and assessment, planning treatment, providing families with prognosis, performing research power analysis, and comparing the efficacy of therapeutic interventions. The global improvement in burns mortality has been attributed to several factors including topical antimicrobials, early burn excision and grafting, multidisciplinary teams, and advances in critical care. But these services are still not enough to reduce the burn related injuries in low income country like Nepal.

The mortality predicting tool was developed more than half century ago by Bull and Squir. One of the most frequently used mortality prediction models is the Baux Index, which was developed as a thesis by a non-burn academic. These were followed by the Abbreviated Burn Severity Index (ABSI) and the Clark mortality prediction model. Better predictions can be obtained using more complex statistical models as Acute Physiology and Chronic Health Evaluation (APACHE) score II, FLAME Score (Fatality by Longevity, APACHE II score, Measured Extent of burn, and Sex), Burns Evaluation and Mortality Study (BEAMS), Prognostic Burns Index (PBI). Till date for surgeons involved in the burn management is familiar with Baux's score. Here we conducted a study to evaluate the usefulness of Baux and ABSI for predicting the Burn related mortality in a Tertiary care hospital of Nepal.

\section{MATERIALS AND METHODS}

All together 150 patient with severe and acute burn was admitted in Burn ward of tertiary care center in Kathmandu over a period of one year. Major Burns (Burns $>15 \%$ Total Body Surface Area Burn (TBSA), dermal burn, Facial flame burn) were included in the study. TBSA was calculated by the Rules of nine. Baux's score was calculated by adding age of the patient and the TBSA. ABSI was measured as shown in the table no. 1. The outcome of major Burn injury between predicted and observed value was compared.

Baux's score $=\%$ of TBSA (Deep burn) + Age of the Patient

Revised Baux Score (Baux Score $=\%$ of TBSA (Deep burn $)+$ Age of the Patient $+(17 \times$ inhalation injury if present 1 and if not 0 )

\section{RESULT}

There were total 92 cases of severe burn injury was
Table 1: Value for ABSI score

\begin{tabular}{|cc|ccc|}
\multicolumn{2}{c}{$\begin{array}{c}\text { Full thickness } \\
\text { burn }\end{array}$} & Variable & Score \\
\hline TBSA & Score & Sex & Male & 1 \\
\hline $1-10$ & 1 & & Female & 0 \\
\hline $11-20$ & 2 & Age & $0-20$ & 1 \\
\hline $21-30$ & 3 & (Years) & 21-40 & 2 \\
\hline $31-40$ & 4 & & $41-60$ & 3 \\
\hline $41-50$ & 5 & & $61-80$ & 4 \\
\hline $51-60$ & 6 & & $80-100$ & 5 \\
\hline $61-70$ & 7 & & & 1 \\
\hline $71-80$ & 8 & & & \\
\hline $81-90$ & 9 & Inhalation & & \\
\hline $91-100$ & 10 & injury & &
\end{tabular}

Table 2: Predicted Threat to life

\begin{tabular}{|c|c|c|}
\hline $\begin{array}{l}\text { ABSI burn } \\
\text { Score }\end{array}$ & Threats to life & $\begin{array}{c}\text { Probability of } \\
\text { survival }\end{array}$ \\
\hline $2-3$ & Very low & $>99 \%$ \\
\hline $4-5$ & Moderate & $98 \%$ \\
\hline $6-7$ & $\begin{array}{l}\text { Moderately } \\
\text { severe }\end{array}$ & $80-90 \%$ \\
\hline $8-9$ & Serious & $50-70 \%$ \\
\hline $10-11$ & Severe & $20-40 \%$ \\
\hline $12-13$ & Maximum & $<10 \%$ \\
\hline
\end{tabular}

Table 3: Age/Gender Distribution

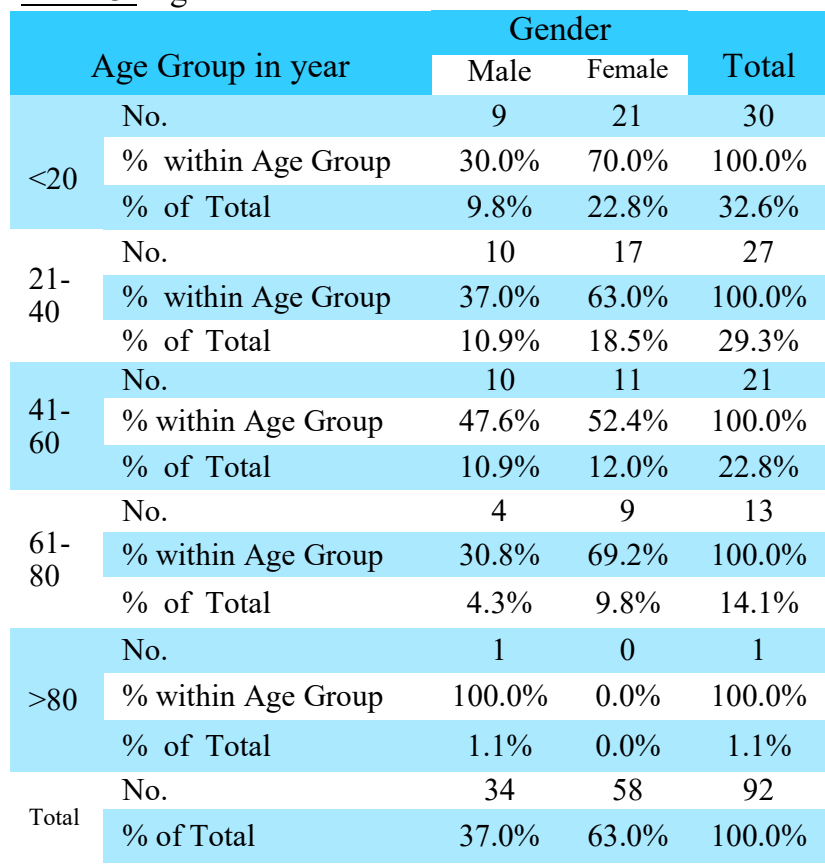

selected for the study among 140 admitted cases. Most (85.8 \%) of were among the young group 1640 years. It comprises $41.3 \%$ in total. In total 63.7 $\%$ were female. The age was ranged from 16 years to 81 years (Table 3 ).

We compared the expected chance of mortality using Baux's score and the observed value of burn injury outcome. The Baux's score was found higher 
Table no.4: Predicted and Observed value of death according to Baux score

\begin{tabular}{|c|c|c|c|c|c|c|}
\hline \multirow{2}{*}{\multicolumn{2}{|c|}{$\begin{array}{l}\text { Baux score } \\
\text { range } \\
\text { Predicted }\end{array}$}} & \multicolumn{4}{|c|}{ Outcome at Discharge } & \multirow[b]{2}{*}{ Total } \\
\hline & & $\begin{array}{c}\text { Recovere } \\
\mathrm{d}\end{array}$ & $\begin{array}{l}\text { Impro } \\
\text { ved }\end{array}$ & $\begin{array}{c}\text { Not } \\
\text { Improved }\end{array}$ & Death & \\
\hline \multirow{2}{*}{$<30$} & No. & 14 & 0 & 0 & 0 & 14 \\
\hline & $\%$ & $100.0 \%$ & $0.0 \%$ & $0.0 \%$ & $0.0 \%$ & $100.0 \%$ \\
\hline \multirow{2}{*}{$\begin{array}{l}31- \\
40\end{array}$} & No. & 9 & 0 & 0 & 1 & 10 \\
\hline & $\%$ & $90.0 \%$ & $0.0 \%$ & $0.0 \%$ & $10.0 \%$ & $100.0 \%$ \\
\hline \multirow{2}{*}{$\begin{array}{l}41- \\
50\end{array}$} & No. & 10 & 0 & 0 & 2 & 12 \\
\hline & $\%$ & $83.3 \%$ & $0.0 \%$ & $0.0 \%$ & $16.7 \%$ & $100.0 \%$ \\
\hline \multirow{2}{*}{$\begin{array}{l}51- \\
60\end{array}$} & No. & 12 & 0 & 0 & 3 & 15 \\
\hline & $\%$ & $80.0 \%$ & $0.0 \%$ & $0.0 \%$ & $20.0 \%$ & $100.0 \%$ \\
\hline \multirow{2}{*}{$>61$} & No. & 15 & 2 & 3 & 21 & 41 \\
\hline & $\%$ & $36.6 \%$ & $4.9 \%$ & $7.3 \%$ & $51.2 \%$ & $100.0 \%$ \\
\hline \multirow{2}{*}{$\begin{array}{l}\text { Tot } \\
\text { al }\end{array}$} & No. & 60 & 2 & 3 & 27 & 92 \\
\hline & $\%$ & $65.2 \%$ & $2.2 \%$ & $3.3 \%$ & $29.3 \%$ & $100.0 \%$ \\
\hline
\end{tabular}

Table 5: Predicted life to Threat and Observed Mortality

\begin{tabular}{|c|c|c|c|c|c|}
\hline \multirow{2}{*}{\multicolumn{2}{|c|}{$\begin{array}{l}\text { Predicted Threat to Life } \\
\text { after burn injury (ABSI) }\end{array}$}} & \multicolumn{4}{|c|}{ Observed outcome } \\
\hline & & \multirow{3}{*}{$\begin{array}{l}\text { Recovered } \\
3 \\
100.0 \%\end{array}$} & \multirow{3}{*}{$\begin{array}{l}\text { Improved } \\
0 \\
0.0 \%\end{array}$} & \multirow{3}{*}{$\begin{array}{l}\text { Not } \\
\text { Improved } \\
0 \\
0.0 \%\end{array}$} & \multirow{3}{*}{$\begin{array}{l}\text { Death } \\
0 \\
0.0 \%\end{array}$} \\
\hline Very low & No. & & & & \\
\hline$(2-3)$ & $\%$ & & & & \\
\hline \multirow{2}{*}{$\begin{array}{l}\text { Moderate }(4 \\
-5)\end{array}$} & No. & 19 & 0 & 0 & 2 \\
\hline & $\%$ & $90.5 \%$ & $0.0 \%$ & $0.0 \%$ & $9.5 \%$ \\
\hline \multirow{2}{*}{$\begin{array}{l}\text { Moderately } \\
\text { severe (5-6) }\end{array}$} & No. & 29 & 1 & 1 & 2 \\
\hline & $\%$ & $87.9 \%$ & $3.0 \%$ & $3.0 \%$ & $6.1 \%$ \\
\hline \multirow{2}{*}{$\begin{array}{l}\text { Serious } \\
(6-7)\end{array}$} & No. & 3 & 0 & 0 & 2 \\
\hline & $\%$ & $60.0 \%$ & $0.0 \%$ & $0.0 \%$ & $\begin{array}{l}40.0 \\
\%\end{array}$ \\
\hline \multirow{2}{*}{$\begin{array}{l}\text { Severe } \\
(8-9)\end{array}$} & No. & 5 & 1 & 2 & 7 \\
\hline & $\%$ & $33.3 \%$ & $6.7 \%$ & $13.3 \%$ & $\begin{array}{l}46.7 \\
\%\end{array}$ \\
\hline \multirow{2}{*}{$\begin{array}{l}\text { Maximum } \\
>10\end{array}$} & No. & 1 & 0 & 0 & 14 \\
\hline & $\%$ & $6.7 \%$ & $0.0 \%$ & $0.0 \%$ & $\begin{array}{l}93.3 \\
\%\end{array}$ \\
\hline
\end{tabular}

mortality in all age group. The mortality was nil in the age group below 30 years and TBSA less than $30 \%$. with The increase in TBSA and Age the mortality was found higher. The increase in Baux's score is related with the increase in mortality but the predicted value and observed value cannot be correlated. During ABSI scoring if the threat to life was found low there was no mortality but the mortality was more than $93 \%$ when life to threat was predicted very serious.(Table no 5.).

\section{DISCUSSION}

This study has shown the higher occurrence $(85.8 \%)$ of burn injury in the young and productive age group. The mortality due to acute severe burn injury during this study was found 29.3\%. Our finding was similar with one the study done in Pakistan which has reported $29.7 \%$ death

rate in burn patients. Many studies have reported mortality rate due to burn injuries. Olaitan et al. reported a $20 \%$ mortality rate in Osogbo, Nigeria. A study from Rotterdam, Netherlands reported a fatality rate of $6.9 \%$. Similarly, Aldemir et al. from Turkey reported a death rate of $6.3 \%$. Mortality has decreased in high income country due to multi disciplinary team approach, early surgery, availability of skin substitutes which is not enough in low income country so the mortality is still high.

Baux's score was a significant association with death of patients. Baux's score more than 60 had the than the observed value of death among the same group. No death had occurred below the Baux's score 30 and there was more than 51\% mortality above the score of 60 . Two patients with advance age more than 80 years and TBSA burn less than $20 \%$ without any co morbid condition had survived. The findings are shown in the table no.4. Out of 92 selected severe burn cases to acute burn ward during the study period, 27 died (mortality rate $29.4 \%$ ). The mortality was higher in the productive age groups (Table no. 2). There was mortality more than $50 \%$. All the patient having the Baux's score less than 30 had survived. The Baux Score continues to provide an indication of the risk of mortality. With medical advances during the past five decades, estimates of death from these models have decreased roughly over time.

ABSI is a useful tool to audit and predict severe burn outcome. By scoring individuals using the Abbreviated Burn Severity Index we can accord a predicted mortality for each patient according to known variables which influence mortality. In our 
ABSI count more than 6 has shown the higher mortality (46-98\%). One study done by Forster N A. Zingg $\mathrm{M}$ et al. Using their extensive database of close to 3000 burns patients treated at their unit has reported that ABSI scoring system is still an accurate and useful tool for the prediction of mortality in burns patients.. Burn management in our part is improving but facilities are still limited so the mortality is high. Though, ABSI scoring for prediction of acute burn death is still acceptable.

\section{CONCLUSION}

Prediction of outcome for patients with major thermal injury is important to inform clinical and financial decision making useful to patients' families and medical professionals regarding their care. Baux score is simple and easy to calculate and all member of the burn management can use it and the revised Baux score is more accurate. But it does not provide reliable correlation with actual mortality in old and young patients. The ABSI scoring is also simple to calculate and it is a reliable and easy tool to predict the burn injury death. Small size of study population, depth of the burn was diagnosed at the time of admission were the limitation of this study.

\section{REFERENCES}

1. Peck MD, Kruger GE, van der Merwe AE, Godakumbura W, Ahuja RB. Burns and fires from non-electric domestic appliances in low and middle income countries Part I. The scope of the problem. Burns. 2008 May;34(3):303-11. DOI:10.1016/j.burns.2007.08.014; PMID:18206314.

2. Forjuoh SN. Burns in low- and middle-income countries: a review of available literature on descriptive epidemiology, risk factors, treatment, and prevention. Burns. 2006 Aug;32(5):529-37. DOI:10.1016/j.burns.2006.04.002; PMID: 16777340.

3. World Health Organization (WHO) [Internet]. Global burden of DISEASE: 2004 summary tables. Geneva: World Health Organization, [cited 2011 Sep 20]. Available from:http://www.who.int/healthinfo/ global_burden_disease/estimates_regional/en/index.html.

4. Park JŌ, Shin $\overline{\mathrm{S} D}$, Kim J, Song $\overline{\mathrm{K} J}$, Peck MD. Association between socioeconomic status and burn injury severity. Burns. 2009 Jun;35(4):482-90. DOI:10.1016/ j.burns.2008.10.007; PMID:19216029.

5. Al Ibran E, Mirza FH, Memon AA, Farooq MZ, Hassan M. Mortality associated with burn injury- a cross sectional study from Karachi, Pakistan. BMC Res Notes. 2013;6:545. DOI:10.1186/1756-0500-6-545; PMID:24354896; PMCID:PMC3878253.

6. Moore EC, Pilcher DV, Bailey MJ, Cleland H, McNamee J. A simple tool for mortality prediction in burns patients: APACHE III score and FTSA. Burns. 2010 Nov;36 (7):1086-91. DOI:10.1016/j.burns.2010.03.013; PMID:20494521

7. Knaus WA, Wagner DP, Lynn J. Short-term mortality predictions for critically ill hospitalized adults: science and ethics. Science. 1991;254(5030):389-94. DOI:10.1126/science.1925596; PMID:1925596.

8. Taylor SL, Lawless M, Curri T, Sen S, Greenhalgh DG, Palmieri TL. Predicting mortality from burns: the need for age-group specific models. Burns. 2014 Sep;40(6):110615. DOI:10.1016/j.burns.2014.03.010; PMID:24846014; PMCID:PMC4143432.

9. Clark CJ, Reid WH, Gilmour WH, Campbell D. Mortality probability in victims of fire trauma: revised equation to include inhalation injury. Br Med J. 1986;292:1303-5. DOI: $10.1136 / \mathrm{bmj} .292 .6531 .1303$

10. Osler T, Glance LG, Hosmer DW. Simplified estimates of the probability of death after burn injuries: extending and updating the baux score. J Trauma. 2010 March;68(3):690 $-7$. PMID:20038856.

DOI:10.1097/TA.0b013e3181c453b3;

1. Tobiasen J, Hiebert JH, Edlich RF. Prediction of burn mortality. Surg Gynecol Obstet. 1982 May;154(5):711-4. PMID:7071708.

12. Khan N, Malik MA. Presentation of burn injuries and their management outcome. J Pak Med Assoc. 2006 Sep;56 (9):394-7. PMID:17091750.

13. Olaitan PB, Jiburum BC. Analysis of burn mortality in a burns centre. Ann Burns Fire Disasters. 2006;19(2):59-62. PMID:21991024; PMCID:PMC3188036.

14. Bloemsma GC, Dokter J, Boxma H, Oen IM. Mortality and causes of death in a burns centre. Burns. 2008;34 (8):1103-7.

DOI:10.1016/j.burns.2008.02.010; PMID:18538932.

15. Aldemir M, Kara IH, Girgin S, Guloglu C. Factors affecting mortality and epidemiological data in patients hospitalized with burns in Diyarbakir, Turkey. S Afr J Surg. 2005;43(4):159-62. PMID:16440590.

16. Roberts G, Lloyd M, Parker M, Martin R, Philp B, Shelley $\mathrm{O}$, et al. The Baux score is dead. Long live the Baux score: a 27-year retrospective cohort study of mortality at a regional burns service. J Trauma Acute Care Surg. 2012 Jan;72(1):251-6. PMID:22310134.

17. Forster NA, Zingg M, Haile SR, Kunzi W, Giovanoli P, Guggenheim M. 30 years later-does the ABSI need revision? Burns. 2011 Sep;37(6):958-63. DOI:http:// dx.doi.org/10.1016/j.burns.2011.03.009; PMID:21493008. 